\title{
La institucionalización de la danza en la Facultad de Bellas Artes en Valdivia: Una historia desde la experiencia de sus bailarines, 1954-1976
}

\author{
Carla Mella Barrientos ${ }^{1}$ \\ Recibido: 26 de enero de 2018 - Aprobado: 23 de abril de 2018
}

\begin{abstract}
Resumen
En el artículo se analiza el proceso de institucionalización universitaria de la danza disciplinaria en Valdivia a mediados del siglo XX. El objetivo es demostrar que su desarrollo surgió debido a la preocupación por la apertura de la cultura a la sociedad civil, entendida como aquellos elementos educativos y artísticos de interés para el Estado chileno, los agentes privados y las municipalidades. El proceso de institucionalización de la danza corresponde a un periodo de transformaciones en torno a la comprensión de la necesidad de integrar en la academia valdiviana el arte escénico, lo que no estuvo alejado de problemas relativos al financiamiento universitario, desastres naturales e interés por parte de las autoridades de mantener el área. Las fuentes utilizadas corresponden a relatos orales de tres destacadas bailarinas vinculadas al campo de la danza en Valdivia, testimonios de carácter principal que encarnan las influencias de escuelas, corrientes y estéticas; documentos vinculados con la historia de la Facultad de Bellas Artes, extraídos del Archivo de la Secretaría General de la Universidad Austral de Chile, archivos personales y notas periodísticas del diario El Correo de Valdivia.
\end{abstract}

Palabras clave: danza disciplinaria, institucionalización, Facultad de Bellas Artes, Universidad Austral de Chile

Chilena. Profesora y Licenciada en Historia, Universidad Austral de Chile. Egresada del Programa Magister en Historia del Tiempo Presente, Universidad Austral de Chile. Esta investigación es fruto del proyecto titulado "Recuperación, análisis y exposición de la trayectoria de la danza en Valdivia (1954-2016)", Folio N 415165, Fondart Nacional, Línea Artes Escénicas/Investigación, 2017, del cual la autora de este artículo es directora y Max Cortés es co-investigador y encargado del fichaje y la sistematización de la información. E-mail: carla.mella.barrientos@gmail.com 


\title{
Institutionalization of Dance in the Fine Arts faculty in Valdivia: A history from its dancers' experience 1954-1976
}

\begin{abstract}
This article analyzes the process of university institutionalization of disciplinary dance in Valdivia in the middle of Twentieth Century. The objective is to show that its development emerged due to the concern about the cultural opening to the civil society known as those educational and artistic elements of interest for the Chilean State, private agents, and municipalities. Such process of institutionalization takes place when people were transforming their understanding about the necessity to integrate Performing Arts in the Academy of Valdivia, which was not far away from problems as university funding, natural disasters, and the interest from authorities to maintain the area. Used sources correspond to verbal stories by three distinguished dancers connected to the dance field in Valdivia, important testimonies personifying influences of schools, trends, and aesthetics; documents related to the history of the Fine Arts Faculty and extracted from the General Secretary Archive of the Universidad Austral de Chile, personal archives, and journalist notes from El Correo de Valdivia newspaper.
\end{abstract}

Keywords: Disciplinary dance, institutionalization, Faculty of Fine Artes, Universidad Austral de Chile.

\section{A institucionalização da dança na Faculdade de Belas-Artes em Valdivia: Uma história desde a experiência de seus bailarinos, 1954-1976}

\section{Resumo}

No artigo analisa-se o processo de institucionalização universitária da dança disciplinar em Valdivia em meados do século XX. 0 objetivo é demonstrar que seu desenvolvimento surgiu devido à preocupação pela abertura da cultura à sociedade civil, entendida como aqueles elementos educativos e artísticos de interesse para o Estado chileno, os agentes privados e as prefeituras. 0 processo de institucionalização da dança corresponde a um período de transformações ao redor da compreensão da necessidade de integrar na academia valdiviana a arte cénica, o que não esteve alheio aos problemas relacionados com financiamento universitário, desastres naturais e interesse por parte das autoridades de manter a área. As fontes utilizadas correspondem a relatos orais de três destacadas bailarinas ligadas ao campo da dança em Valdivia, testemunhos de caráter principal que encarnam as influências de escolas, correntes e estéticas; documentos ligados à historia da Faculdade de Belas-Artes, extraídos do Arquivo da Secretaria Geral da Universidade Austral do Chile, arquivos pessoais e recortes da imprensa pertencentes ao jornal 0 Correio de Valdivia.

Palavras-chave: dança disciplinar, institucionalização, Faculdade de BelasArtes, Universidade Austral do Chile 


\section{Introducción}

La creación de la Universidad Austral de Chile en 1954 fue fruto de un proyecto gestado al calor de conversaciones y preocupaciones que lograron unificar los objetivos de agrupaciones privadas, entre ellas la "Sociedad Amigos del Arte", en torno al desarrollo de la región y sus proyecciones a nivel nacional. El principal propósito de esta creación fue incorporar el modelo de universidad científica vigente en Europa y Norteamérica (Almonacid, 2004: 178), lo que significó la apertura y la institucionalización -entendida en este artículo como el fenómeno de regulación social y política realizada por una institución, y cooptada por ella- de disciplinas necesarias para el fortalecimiento de la economía regional, como Ingeniería Técnica Agraria, Medicina Veterinaria, Filosofía y Educación, Bellas Artes e Ingeniería Técnica Forestal (Memoria Institucional UACh 1955-1956, 1956).

La Universidad Austral, a partir de ello, emergió como una alternativa al centro del desarrollo metropolitano, con ideales fuertemente influenciados por la modernización industrial de la sociedad valdiviana, lo que fue respaldado por una concepción de interés cultural que acompañó las proyecciones estatales y municipales del periodo, ligadas particularmente a la masificación del arte y la educación en la sociedad civil. ${ }^{2}$ De esta manera, con una amplia gama de actividades culturales-artísticas, que incluyeron "proyecciones de cine, exposiciones pictóricas y plásticas, conciertos musicales y recitales, ballet, teatro" (Almonacid, 2004: 182), se creó en el año 1954 la Facultad de Bellas Artes, con el objetivo de organizar y patrocinar el arte en el sur de Chile, mediante la fusión del Instituto de Extensión Cultural y sus escuelas anexas de Danza, Artes Plásticas, Coros y Conservatorio de Música (Memoria Institucional UACh 1955-1956, 1956: 38), escuelas lideradas por artistas musicales, escénicos y plásticos, extranjeros y chilenos.

El objetivo de este artículo es analizar la integración del arte escénico al proyecto universitario, lo que representó su apertura en el sur del país. Interesa particularmente examinar la trayectoria del campo de la danza disciplinaria,

2 Desde el ámbito municipal, se puede observar la creación de la Ley № 11.860, que fija el texto refundido de la Ley de organización y atribuciones de las municipalidades (1955), legislación que les confirió a los municipios la obligación de "Subvencionar teatros y diversiones públicas honestas y gratuitas o a bajos precios para el pueblo, pudiendo costear éstas de sus propios fondos o con la ayuda económica con que leyes especiales concurran al efecto", y "Como encargadas de promover la educación, la agricultura, industria y comercio; de cuidar de las escuelas primarias y demás establecimientos de educación que se paguen con fondos municipales, y de auxiliar a la Beneficencia Pública, corresponde a las Municipalidades", artículos 12 y 53, respectivamente. 
en el sentido de Pierre Bourdieu, ${ }^{3}$ debido a que su cooptación institucional expresa una temprana integración universitaria de un área desarrollada de manera disciplinar en el centro del país, lo que manifiesta el interés por parte de los agentes privados de diversificar las posibilidades de expresión artística en la región. En este artículo se postula que el desarrollo de la etapa de institucionalización a mediados del siglo XX en Chile surgió debido a la preocupación por la apertura de la cultura a la sociedad civil, entendida éste como aquellos elementos educativos y artísticos de interés para el Estado chileno, los agentes privados y las municipalidades. A pesar de la alta tasa de analfabetismo urbana y rural de la provincia (XII Censo General de Población, 1952), las transformaciones económicas de la ciudad de Valdivia, vinculadas a la progresiva industrialización, obligaron a instalar ciertos cánones culturales asociados al progreso y el esplendor de las ciudades europeas industriales, lo que derivó en la creación de la primera universidad del sur-austral chileno y la institucionalización de disciplinas de interés para sus creadores, entre ellos la agrupación privada "Sociedad Amigos del Arte". Esta situación se fracturó con el megaterremoto de 1960 que azotó gran parte del sur de Chile, siendo Valdivia el epicentro de la destrucción material y social, lo que significó una reestructuración de las condiciones de vida de la población y todo lo asociado a ella, incluyendo el ejercicio artístico y escénico, debido al perjuicio económico que generó en la ciudad. Esta coyuntura determinó el posterior desarrollo de la danza valdiviana, ya que muchos de los profesores contratados para extender y diversificar la oferta de la Universidad Austral de Chile migraron a otras provincias del país debido a que la institución optó por dejar en receso algunas áreas impulsadas desde su surgimiento, lo que obligó posteriormente a vincularse con las áreas de extensión promovidas por la municipalidad de Valdivia, salvaguardando el desarrollo artístico de la universidad a través de estos lazos institucionales.

También se argumenta que el florecimiento estético y escénico desarrollado hasta la década del setenta se empañó a nivel universitario-institucional por la irrupción del Golpe Militar en septiembre de 1973, que obligó a cerrar gran parte de las escuelas e institutos de la Facultad de Bellas Artes debido a la reestructuración de la organización institucional, situación que en la zona metropolitana permitió el desarrollo de la "danza independiente", entendida como aquella que surgió fuera de las instituciones del Estado a través de la autogestión (Hurtado y Alcaíno, 2010)4, y que, en otras zonas del país, como Valdivia, determinó un nuevo enlace institucional con la municipalidad de

3 "Espacios estructurados de posiciones (o de puestos) cuyas propiedades dependen de su posición en estos espacios" (Bourdieu, 2008: 112). Si bien es necesario reconocer todos estos aspectos, interesa en esta investigación analizar la posición de los bailarines en torno a la estructuración del campo, sus experiencias y su influencia en los cambios.

4 Para ver más sobre este tema revisar: Cordovez et al., 2009; Cifuentes, 2007 y Ponce, 2014. 
la ciudad. Debido a ello, es importante reconocer que la experiencia de la danza en esta investigación constituye un campo de interacción que va más allá de derroteros estéticos y performáticos, ya que en él se materializaron influencias políticas que operaron desde el exterior y el interior, construyendo relaciones y trayectorias de vida.

Para esta investigación se utilizarán tres testimonios respecto del proceso de institucionalización de la danza en Valdivia, cuyo punto de agudización se encuentra en 1954, y de fractura en 1976, hasta el momento de transformación neoliberal. El uso de sus testimonios entregará parte de sus biografías, en las que se encarnan los cambios y continuidades sociales, económicas y políticas del país y la región. A partir de sus relatos se revelará "un tipo de sociabilidad informal, y es en esta interacción dinámica en la que se traza una memoria colectiva" (Sanz, 2005: 9). Es decir, desde la presentación de sus memorias de oficio, a partir del panorama sugerido de sus relatos individuales, será posible identificar cómo se construyó la organización institucional del campo de la danza, reconociendo en el territorio valdiviano elementos significativos de análisis, dados los diversos niveles que en el presente configuran el juicio sobre el pasado desde la óptica de sus participantes.

\section{La experiencia de los bailarines en la Escuela de Danza, 1954-1976}

Al hablar de movimiento corporal -y su sistematización a través de técnicas y disciplina-, el cuerpo, en tanto categoría de construcción social, como producto de la socialización, lugar de representación y reproducción (Bourdieu, 2007), emerge como un ente mediador cuya performance es parte y representación del movimiento histórico. De esta forma, es posible comprender la conexión permanente de las manifestaciones del cuerpo con el tiempo y el espacio, ya que su captura se ha encarnado en los intereses artísticos y estéticos de coreógrafos, en la expresión corporal de bailarines y en la atención del público. Estas disposiciones han generado trayectorias, desplazamientos que construyeron historias de vida impregnadas de rupturas y continuidades, cuya vivencia expone visiones empapadas de intereses que se conectan directamente con la práctica de la danza en los territorios.

Para su estudio será necesario tomar en cuenta la estructura de la red, de aquel tejido unificador del oficio escénico, y no solo de la "carrera o una vida como una serie única y suficiente para sí de acontecimientos sucesivos sin más vínculo que la asociación a un sujeto" (Bourdieu, 2011: 383). A partir de ello, la trayectoria social será comprendida como "una manera singular de recorrer el espacio social, donde se expresan las disposiciones del habitus; cada desplazamiento hacia una nueva posición, en tanto que implica la 
exclusión de un conjunto más o menos amplio de posiciones sustituibles" (Bourdieu, 2011: 384-385). El análisis desde la perspectiva de las historias de vida nos conducirá a conocer el proceso de institucionalización del arte en Valdivia a través de la Escuela de Danza en la Facultad de Bellas Artes, mediante el análisis de aquellos parámetros de consagración, vanguardia, éxitos, fracasos, etc., que estructuraron la emergencia de un campo escénico en una universidad, la primera del sur austral chileno, a mediados del siglo XX.

\section{La danza, un oficio de porfía y pasión}

Ana María se integró a la danza en un momento de proliferación intelectual y económica en el sur de Chile, momento que albergó un periodo de desarrollo artístico, gracias al rol que adquirieron las municipalidades a nivel nacional en torno su desarrollo ${ }^{5} \mathrm{y}$ el aporte de los clubes sociales de origen binacional, como el "Club Alemán" (mediados del siglo XIX), el "Centro Español" (creado en 1911) y el "Club Valdivia" (1882-1950). Su familia la llevó desde muy pequeña como asistente a la variada actividad artística de mediados del siglo XX, promovida principalmente por los agentes privados, quienes manifestaron su interés por generar en la ciudad un ambiente favorable para el desarrollo de "valores espirituales", objetivo de los círculos culturales (El Correo de Valdivia, 28-I-1955), quienes habilitaron espacios físicos para su ejecución, como el "Teatro Cervantes" y el "Club de la Unión" (Ex Club Alemán) (Ana María Cabello, entrevista personal, 2017), en donde transitaron brevemente importantes bailarines vinculados al Instituto Alemán de Valdivia y la "Sociedad Amigos del Arte": hablamos de Lotte Pieper, Maruja Carvallo Frick, Elma Klempau y Herbert Belkner (Guarda, 2001: 642).

Estos exponentes de la danza europea, posterior a su llegada al sur, instalaron pequeñas academias para niñas y niños de todas las edades, lo que permitió el desarrollo de espectáculos escénicos que abrieron espacios para preescolares, y cuya manifestación expresó el vínculo de la ciudad con los bailarines europeos, como la presentación en el año 1918 de la bailarina rusa Anna Pávlova realizada en el extinto Teatro "Edén". Veinte años más tarde también se presentarían sus compatriotas Vadim y Mina Sulima. (Guarda, 2001: 642).

Ley $N^{\circ} 11.860$ que fija el texto refundido de la Ley de organización y atribuciones de las municipalidades (1955): " $5^{\circ}$ Las Municipalidades destinarán anualmente el uno por ciento, a lo menos, del total de sus ingresos ordinarios a la fundación, sostenimiento o subvenciones de bibliotecas populares, teatro popular, estímulo a la producción artística, literaria y musical; museos, colegios, escuelas nocturnas, establecimientos de enseñanza técnica, vocacional o de cultura física; estaciones agronómicas y establecimientos modelos agrícolas o industriales". 


\section{Figura 1}

Recital de danzas, Elma Klempau y sus alumnas

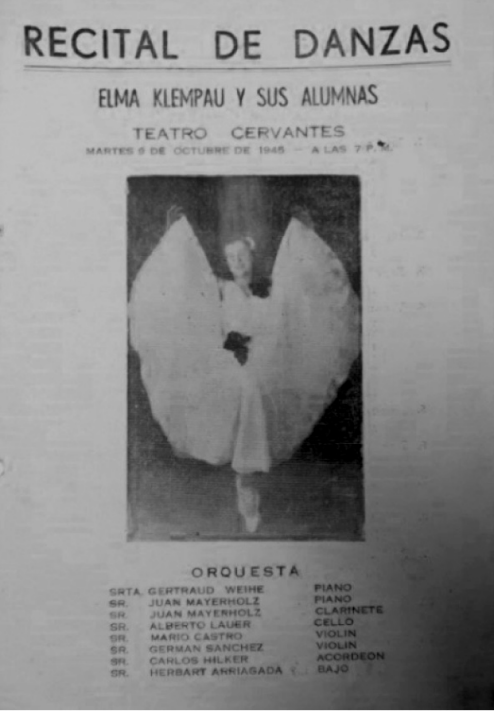

Fuente: Archivo Personal Ana María Cabello, 9-X-1945

\section{Figura 2}

Gran Recital de Danzas, Herbert Belkner y sus alumnas

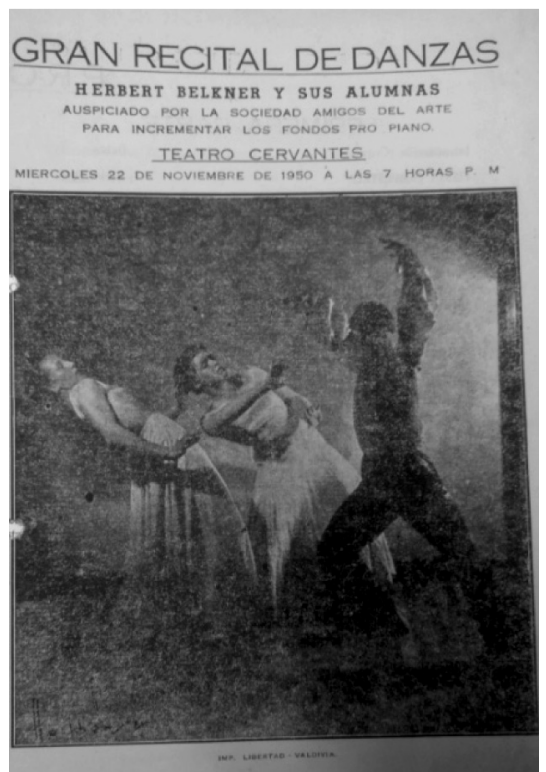

Fuente: Archivo Personal Ana María Cabello, 22-XI-1950 
Figura 3

Ana María Cabello c1945

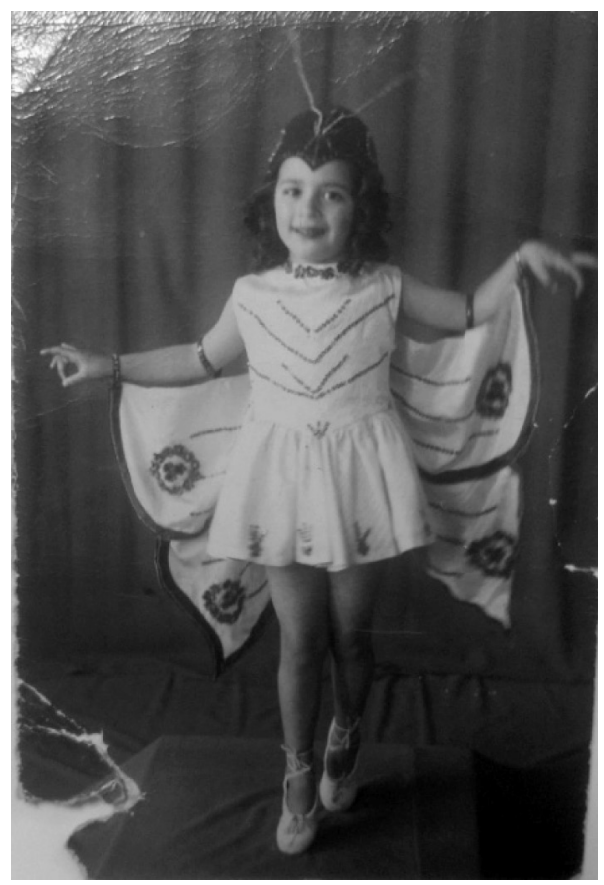

Fuente: Archivo Personal Ana María Cabello

A mediados del siglo XX, con solo cuatro años, una pequeña Ana María incursionó como solista en algunas presentaciones, experimentando en esta primera formación el tránsito de las instalaciones del Instituto Alemán, desde su sede en calle Picarte, hacia el edificio de la desaparecida Protectora, locales que albergaron las clases del profesor Belkner y su pareja pianista. Herbert Belkner, bailarín alemán y discípulo disciplinar del maestro Kurt Jooss, ex bailarín del Teatro de la Ópera de Berlín -compartiendo escenario con Ernst Uttoff, quien visitó Valdivia en algunas ocasiones-, formó a sus primeros bailarines a través de una herencia escénica de posguerra de fusión clásica, moderna y expresionista, que impregnó el campo de la danza a las primeras exponentes además de Ana María: Manuela Castillo, María Eugenia Charpentier, María Carvallo, entre otras. ${ }^{6}$ A partir de ello la academia, entendida como un espacio de constante creación y perfeccionamiento artístico autónomo, se tomó el espacio valdiviano.

$6 \quad$ Nombres señalados en documento Gran recital de danzas Herbert Belkner y sus alumnas (1950), Archivo personal, Ana María Cabello. 
Los primeros pasos de este campo fueron acompañados por el desarrollo económico en el sur de Chile, y particularmente Valdivia, cuyo florecimiento industrial estuvo representado por la instalación de fábricas e industrias desde mediados del siglo XIX (Almonacid, 2013) como la Sociedad Industrial Hoffmann, Fábricas de calzados Rudloff, Weiss y Pérez, Fábrica de cecinas Liewald y Schwenke, entre otras. Este fenómeno creó las primeras intenciones por parte de agrupaciones como la Sociedad Médica de Valdivia, el diario El Correo de Valdivia, el Club de La Unión y comunidades empresariales, de generar en la ciudad un modelo de ciudad cultural apegada al progreso y la modernización ${ }^{7}$ y la necesidad de establecer y masificar la cultura entendida como el arte y la educación a la población. Carlos Schmidt, presidente del "Círculo valdiviano en Santiago" lo señaló en una entrevista al diario El Correo de Valdivia: "El progreso de Valdivia es asombroso y el entusiasmo, patriotismo e interés de sus habitantes por superarse en todo lo que dice adelanto para la ciudad es digno de todo elogio" (El Correo de Valdivia, 13-I-1955).

Este panorama permitió la creación de la primera universidad del sur austral chileno, la Universidad Austral de Chile, iniciativa que lideró el médico Eduardo Morales, aglutinando los ideales del mundo privado. Morales sintonizó con la necesidad de generar un espacio intelectual en Valdivia. A su llegada a la ciudad, en 1939, señaló en su libro Remembranzas de una universidad Humanista: "Desde el primer día, Carmen y yo nos sentimos inquietos porque el panorama cultural nos pareció muy pobre" (Morales, 2014: 54). Pronto se conformó la "Sociedad Amigos del Arte", que realizó múltiples espectáculos que permitieron financiar, por ejemplo, instrumentos y "actividades en torno a la poesía, la pintura y la música" y danza, mediante constantes patrocinios a las actuaciones de agrupaciones como el Victory Ballet de Santiago (Petersen et al., 2013: 9). Así, surgió la necesidad de generar un espacio de conocimiento consolidado en Valdivia con la intención de formar a los jóvenes y potenciales profesionales de la ciudad bajo la pretensión de que los "alumnos miren a sus maestros con aquel respecto y admiración que los antiguos experimentaron por la profesión más hermosa del hombre; y que a su vez nuestros profesores contemplen a sus alumnos con la veneración y el amor que el artista pone en la obra de sus manos" ${ }^{8}$

\footnotetext{
"En síntesis hay que levantar a nuestro pueblo al plano de la cultura, de la civilización y el progreso, incorporarlo al reino del espíritu y de la belleza, abrir ante sus ojos maravillados las paginas inmortales de la cultura nacional, desde Ercilla hasta Neruda, dotarlos de conocimientos técnicos, darles un nivel de vida humano. En una palabra, hay que hacer una realidad la democracia", en "Una nueva luz: la Universidad Austral", del profesor Carlos Jobet Virreira, El Correo de Valdivia, 14-III-1955.

8 Carta del rector Eduardo Morales a Vittorio di Girolamo, 4-IX-1958, en Archivo Secretaría General, Universidad Austral de Chile.
} 
Debido a estas preocupaciones se creó rápidamente una facultad con el objetivo de desarrollar un proyecto universitario cultural de raigambre modernizadora, que representó un nuevo espacio para la expresión artística, musical y escénica de la provincia de Valdivia, respondiendo al proyecto moderno de arte, aquel que partió desde las orientaciones del iluminismo ilustrado y donde el paradigma axiológico fue el progreso (Cancino et al., 2009: 31). Durante este proceso, el campo de la danza, que históricamente en el sur de Chile se desarrolló fuera de espacios institucionales, fue intervenido, cooptado y liderado por connotados bailarines que llegaron a dirigir la naciente Escuela de Danza: Ana Blum, Alfonso Muñoz y Liselott Warch, y el ayudante Jaime Yory Osses, profesores que a pesar de poseer trayectorias de oficio fuera de la región creyeron en el proyecto universitario. Ana relata este proceso como un punto de inflexión, debido a que los alumnos de esas academias quedaron de inmediato dentro de la UACh, puesto que la Facultad de Bellas Artes se creó debido a la fusión del Instituto de Extensión Cultural y sus Escuelas Anexas de Danza, Artes Plásticas, Coros y Conservatorio de música. (Memoria Institucional UACh 1955-1956, 1956: 34) lo que permitió un número importante de asistentes a clases, a pesar de la diferencia de edad. ${ }^{9}$ La vivencia corporal se transformó, el apoyo en este sentido por parte de una institución generó un respaldo y un reconocimiento al arte valdiviano a nivel nacional.

\section{Institucionalización de la danza: la apertura de la Facultad de Bellas Artes en Valdivia}

Con un importante porcentaje de alumnado, que bordeaba las 90 alumnas, habiendo la totalidad de ellas sido parte de la enseñanza primaria y secundaria de la ciudad, se creó la Escuela de Danza con tres cursos: preparatorio, inicial y avanzado, y seis años de estudio. La formación escénica se había instalado ya desde el año 1954, pero se oficializó el 15 de mayo de 1956 (Memoria Institucional UACh 1955-1956, 1956: 37), convocando a niñas y niños de la ciudad, quienes, con el apoyo económico de sus familias, lograron entrar y costear la carrera que los llevaría a forjar sus estudios de danza.

El proceso de formación de esta Escuela, sin embargo, estuvo tensionado por los diversos problemas que algunas familias de sus estudiantes tuvieron para financiar los altos costos de su estadía en la casa de estudios. En 1958, la profesora Liselott Warch se refirió a esta necesidad, a partir del pago de onerosas cuotas mensuales y bimestrales, adjudicando este problema además al poco desarrollo "profesionalizante" de la danza en la Facultad, lo que con

9 Debido al gran número de estudiantes matriculados en los cursos iniciales, el curso en referencia se tuvo que dividir en dos. Memoria Institucional UACh, 1955-1956, 1956: 37, en Archivo Secretaría General, Universidad Austral de Chile. 
mayor razón demostraba que esta carrera no funcionaba de igual manera a otras, por lo tanto, urgente era bajar su arancel:

" $2^{\circ}$ Los estudios de la Escuela de Danza tienen por objetivo el aprendizaje de una disciplina artística que puede llevarle, con el perfeccionamiento técnico, a realizarse como bailarina. Por lo tanto, no conduce a la formación (luego de seis años de estudio), de un profesional del arte escénico, ya que en muchos de los casos el perfeccionamiento artístico y técnico requiere toda una vida de intensa dedicación y estudios, el que logra un bailarín (en su mayoría) años más tarde de ingresar de la Universidad o una academia superior de estudios coreográficos.

$3^{\circ} \mathrm{Al}$ cabo de 6 años de estudios regulares el alumno de ballet con una "Licenciatura" en el arte de la danza, título de dudosa categoría universitaria para muchos, por cuanto el alumno no está capacitado del todo ni como para desempeñarse como bailarín ni como profesor de ballet salvo que hubiere tenido una preparación pedagógica especial para desempeñarse como docente o condiciones artísticas relevantes para integrar un cuerpo de ballet profesional". ${ }^{10}$

Esta situación generó controversias, ya que representó las deficiencias económicas que a nivel institucional tuvo la Universidad Austral para administrar todas sus facultades, expresando las debilidades del sistema implantado en 1955. De esta manera, Bellas Artes en 1958 fue reconocida por las autoridades debido a que dentro de ella faltaba "el nivel propiamente universitario" (Acta Consejo UACh, 1958, en Almonacid, 2004: 189), razón por la que cerraron en el año 1959 la Escuela de Danza"11, el curso docente de artes plásticas, disminuyendo además el trabajo del conservatorio (Almonacid, 2004).

Las manifestaciones sísmicas a inicios de la década del sesenta coronaron los ánimos institucionales de modificar la situación de Bellas Artes, ya que el megaterremoto y maremoto "dañó algunas provincias y destruyó una ciudad, y la mitad que restaba de otra provincia destruida por el tiempo"12, lo que llevó a la migración de profesionales fuera de la ciudad y el país debido a la falta de recursos económicos para completar la planta docente. ${ }^{13} \mathrm{~A}$ ello se sumó la reestructuración de las facultades en el año 1962, al mando del

10 Carta de Liselott Warch Muller de Franco al decano Vittorio di Girólamo. 17-V-1958, en Archivo Secretaría General Universidad Austral de Chile.

11 Junto con dar a conocer a los primeros egresados de la Facultad de Bellas Artes, se señaló que "en la actualidad esta Facultad solo cuenta con dos escuelas: la de Artes Plásticas y el Conservatorio de Música. Por razones de economía y organización se han cerrado las de Danza, Coros y Teatro", El Correo de Valdivia, 2-X-1960.

12 Carta de Dr. Eduardo Morales Miranda, rector de la Universidad Austral de Chile a El Correo de Valdivia 16-IV-1961 en Pelusa de Van de Maele, 1996: 367.

13 Decreto Rectoría del 13-III-1963 que declara la insuficiencia de docentes y disponibilidades financieras de la Universidad, además de señalar que las dependencias no eran las adecuadas para albergar a los alumnos, en Archivo Secretaría General Universidad Austral de Chile. 
rector Félix Martínez Bonati, entre "facultades con la nomenclatura 'básicas y académicas' (Ciencias Naturales y Matemáticas, Filosofía y Letras y Bellas Artes) y 'profesionales' (Ciencias Agrarias, Ingeniería Forestal, Medicina Humana, Medicina Veterinaria y Educación)". ${ }^{14}$

La danza disciplinaria fue igualmente golpeada por esta situación, ya que sus principales profesores se fueron de la ciudad, desamparando a los alumnos interesados por practicar esta disciplina perteneciente a la oferta que ofrecía la Universidad. A pesar de ello, Lady Muñoz, alumna de Maruja Carvallo y posteriormente de Liselott Warch y Alfonso Muñoz, se quedó en Valdivia para forjar una academia junto a Osvaldo Bastidas, la que estuvo integrada por importante número de estudiantes. En una entrevista al diario El Correo de Valdivia señaló el ambiente favorable para desarrollar y fomentar actividades artísticas, ya que "existe un marcado interés por el estudio del ballet" (EI Correo de Valdivia, 2-XII-1962). Sin embargo, expresó a su vez las necesidades del arte en el país, señalando que "desgraciadamente, todo ello fue trabado por la escasez de medios económicos, locales adecuados y la ausencia de una política municipal o estatal que ayude al mantenimiento de este tipo de actividades" (El Correo de Valdivia, 2-XII-1962). De esta forma, durante gran parte de la década de los sesenta la danza quedó replegada nuevamente a las academias de destacadas bailarinas clásicas y no en la universidad.

\section{Figura 4}

Magnifica presentación cumplió ayer Academia de Ballet Muñoz-Bastidas

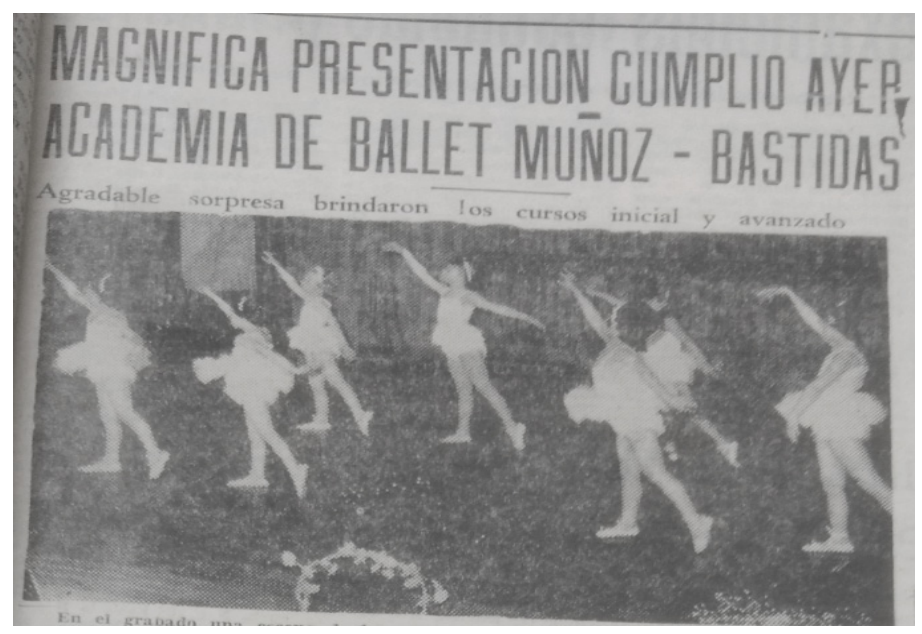

Fuente: El Correo de Valdivia, 2-XII-1962 14 Decreto de Rectoría Universidad Austral de Chile 11-XII-1962, en Archivo Secretaría General,
Universidad Austral de Chile. 
El periodo de receso permitió el desarrollo de nuevos espacios de danza, como el que formó Matilde Romo, directora, profesora, coreógrafa, bailarina y posterior prodecana de la Facultad de Bellas Artes, quien creó en 1964 el Ballet Austral, espacio que propuso extender sus actividades fuera de los escenarios valdivianos, particularmente a la geografía sureña durante los veranos (El Ballet Austral, Archivo Personal Ana Cabello, 1968). Matilde generó el primer impulso de tránsito colectivo y extensión de la danza desde Valdivia hacia otros lugares, como la presentación en el cerro Ñielol en Temuco, las estaciones de Endesa en Pilmaiquén y Pullinque y Enap en Tierra del Fuego (El Ballet Austral, Archivo Personal Ana Cabello, 1968), primer paso además hacia el camino de la profesionalización de esta especialidad. La llegada de Matilde permitió el reflorecimiento de la danza en Valdivia, ya que no solo fue llamada por la universidad para realizar clases y reabrir la Escuela de Danza a fines de la década del sesenta, sino que vinculó su quehacer profesional a la Casa de la Cultura, institución municipal, a través de la formación del Ballet Austral, que incursionó en la danza moderna por medio de presentaciones como Peter Pan, Lunik a go-go y la estilización de bailes con música de jazz sinfónico de Duke Ellington, además de presentaciones en el Hospital John Kennedy ante el público integrado por profesionales y pacientes. De esta forma, no solo la universidad sustentó el oficio del bailarín sino también otros lugares de formación.

\section{Figura 5}

Ballet Austral, 1968

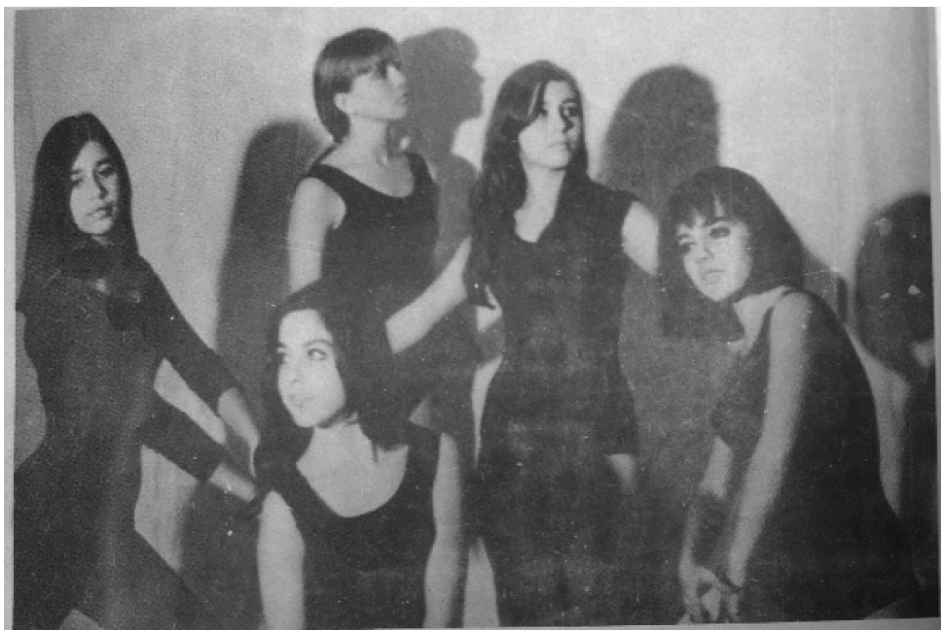

Fuente: Archivo personal Ana María Cabello

Progresivamente, la recomposición de la danza en la institucionalidad universitaria se hizo realidad, lo que además del impulso regional dirigido por 
los bailarines que siguieron fomentando su especialidad posterior al cierre en 1958, se sustentó por las transformaciones políticas del país. En el año 1969 Valdivia, ya en proceso de reconstrucción territorial debido al desastre natural de 1960, presentaba una progresiva recuperación. A esto se sumó el incremento del presupuesto en educación del gobierno de Eduardo Frei Montalva, que llegó a la suma E 1.555 .000 .000 en 1968, a diferencia de los $E^{\circ} 698.000 .000$ de 1964 (Mensaje Presidencial al Congreso, 1968: 41), destacando su política en pro del alfabetismo urbano y rural, además del fortalecimiento de la educación por medio de la Reforma Educacional que tuvo como objetivo igualar las oportunidades "para todos los chilenos para llegar a los más altos niveles del saber y la cultura [como], la dignidad de cada hombre y mujer chilena para organizarse libremente y luchar en defensa de sus legítimos derechos" (Frei, 1993: 399). Ximena, una aventajada adolescente, vivió este proceso a raíz de su integración en etapa escolar al taller escolar de una alumna de Herbert Belkner, Margarita Becerra. Paralelamente a ello, se desempeñó como alumna en la primera orquesta de Ernesto Guarda, destacado músico valdiviano, y en la academia de Lady Muñoz, estudiante de la primera oleada de la Escuela de Danza. El paso de Ximena por la Escuela de Danza lo vivió desde muy pequeña: entró en séptimo básico, lo que le impidió comenzar sus clases de intérprete; sin embargo, su paso por la Escuela significó su unión definitiva con la danza:

"era un ambiente espectacular, algo que yo he vuelto a ver después en películas porque nosotros nos paseábamos por el conservatorio con malla con nuestra ropa de training, tu pasabas por una sala y estabas escuchando música, estabas escuchando el piano, pasabas por otro lado sentías las voces del canto, pasabas por otra sala estaba la gente de teatro, siempre los fines de semanas estaban los viernes culturales en que nos juntábamos todos, los viernes culturales eran pero una elite en Valdivia en cuanto al arte y la cultura, mucha sociabilidad y todos participábamos de esos viernes culturales". (Ximena Schaaf, entrevista personal, 2017)

Aquellos espacios de comunicación disciplinar fueron momentos de encuentro en los que se programaron las diferentes especialidades de la Facultad de Bellas Artes, entre ellas teatro, danza, artes plásticas, coros y conservatorio, como también los "clásicos universitarios", en los cuales, además, se vincularon con la Universidad Técnica del Estado. Lo que significó un estímulo para alumnos y profesores:

"de repente era un concierto de piano, de repente era el coro el que cantaba, de repente éramos nosotros que bailábamos, la gente del teatro que actuaba, entonces nos conocíamos todos, éramos una gran familia de la música, del teatro, de la danza, tu bajabas al subterráneo, ahí estaba funcionando todo lo que era luthería, pintura entonces era 
muy mágico el ambiente era muy lindo si por eso salía del colegio y yo a las cuatro de la tarde estaba en la facultad y no me movía nadie hasta que llegaba la noche". (Ximena Schaaf, entrevista personal, 2017)

En este momento llegaron maestros a la ciudad, quienes se trasladaron desde Santiago y que paralelamente dictaban clases en Temuco, como Osvaldo Lizana, destacado maestro distinguido por su conocimiento de la metodología del ballet ruso y pupilo de Charles Zosedensi, quien realizó clases a Ximena. En este momento, el Teatro Cervantes se volvió un espacio de unión para toda la Facultad, comunidad que por lo demás fue convocada en espacios como el Coliseo Municipal y la Costanera:

"era el único teatro que había, entonces todos los espectáculos de danza de teatro de las grandes compañías llegaban al Teatro Cervantes, se hacían grandes montajes. Matilde Romo, que era la directora de la carrera, hacía montajes muy grandes, muy apoteósicos, y Valdivia en ese minuto estaba muy identificada con la danza clásica, ese es un punto súper importante, en ese minuto de danza contemporánea no existía a lo mucho danza moderna por ahí, pero yo recuerdo, o sea entre comillas, lo que podría llamar danza moderna, un montaje que justamente hizo Matilde Romo que se llamaba "Nuestra ciudad" y que interveníamos con ropa por así decirlo más de calle y que tomó como personajes de la época en ese minuto y pero los montajes en sí eran netamente clásicos, una Sílfides, Lago de los Cisnes, Cascanueces, Coppelia, a ese nivel de montaje, y la sociedad de Valdivia llenaba para las funciones de danza el Teatro Cervantes, entonces era todo un tema además social, las funciones de danza involucraban a la sociedad valdiviana del minuto". (Ximena Schaaf, entrevista personal, 2017)

La reapertura de la Escuela de Danza -que según las Memorias de Institucionales de la Universidad (1969, 1970, 1973 y 1974) inició en el año 1970, con 22 alumnas, como parte de la Facultad de Bellas Artes- integró dentro de su formación las nuevas propuestas en torno a la comprensión de la cultura, todo ello asociado a la apertura de la experiencia escénica, por medio de grandes montajes, y el uso del espacio físico como un intermediario artístico -como el Río Calle Calle- que significó la alianza de todos los estudiantes de Bellas Artes.

Waltraud se integró a la Escuela de Danza en agosto del 1972, después de su paso entre 1964 y 1969 por la academia de las destacadas bailarinas Lady Muñoz y Carmen Contreras, cuando se hizo "el llamado a jóvenes varones y mujeres, que tuvieran conocimiento en danza sobre los dieciséis años y profesores de Educación General Básica para formar parte de un programa de estudios que iba tardar tres años" (Waltraud Püschel, entrevista personal, 2017), Como fruto de ello obtendrían el título de monitores. La noción de 
monitoría se generó en distintos centros de capacitación e institutos durante la Unidad Popular, para poder expandir el trabajo de las artes y la cultura con la finalidad de formar:

"una plataforma en las distintas áreas, tanto artísticas como también en otras especialidades, en tanto pudiesen llegar hacia las poblaciones, por ejemplo, a centros comunitarios y desde allí sacar los talentos, en este caso en el mundo de la danza, para llevarlos a estas escuelas de danza que, en este caso, se estaban formando bajo el alero de la Facultad de Bellas Artes de la Universidad Austral de Chile". (Waltraud Püschel, entrevista personal, 2017)

Figura 6

Osvaldo Lizana con sus alumnas, s/f

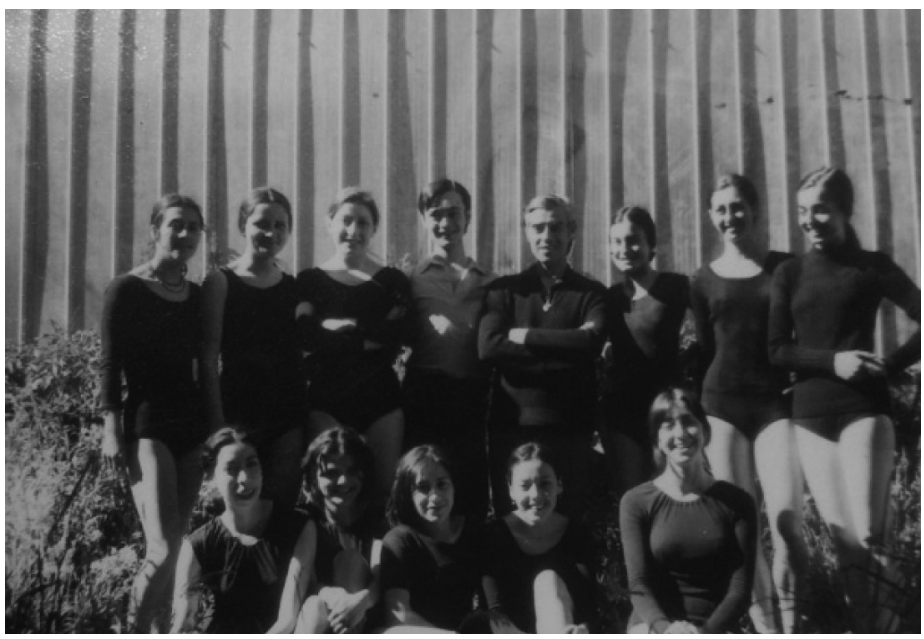

Fuente: Archivo personal Ana María Cabello

A partir de ello comenzó el trabajo artístico fuera del espacio universitario, con el objetivo de formar profesionales de la danza a pesar de no estar cerca del campo académico, otorgando oportunidades de formación y ejerciendo, a su vez, un trabajo de extensión efectivo, dada la conexión entre las esferas del conocimiento popular y la academia. Matilde Romo, precursora de esta iniciativa, "se percató durante las charlas de divulgación de ballet en las escuelas básicas de la ciudad que en la mayoría de esos establecimientos había personas que enseñaban danza pero con escasos o con ningún conocimiento sobre la técnica de este difícil arte" (El Correo de Valdivia, 10-VIII-1972), lo que la motivó a crear el curso y un taller experimental de investigación y creación.

Este proyecto, que se materializó en función de una comprensión de democratización de la cultura, en tanto conocimiento y arte, forjó una línea 
de trabajo directa con la sociedad civil, lo que permitió la formación de monitores dentro del proceso de institucionalización de la danza en la Universidad Austral de Chile y la entrega de becas por parte de entidades privadas ${ }^{15}$ para niños y niñas de escasos recursos que quisieran practicar danza, concretando la iniciativa del gobierno de la Unidad Popular:

"el nuevo Estado procurará la incorporación de las masas a la actividad intelectual y artística, tanto a través de un sistema educacional radicalmente transformado, como a través del establecimiento de un sistema nacional de cultura popular. Una extensa red de Centros Locales de Cultura Popular impulsará la organización de las masas para ejercer su derecho a la cultura". (Programa Básico Unidad Popular, 1969: 28)

La creación de este nuevo sistema de cultura popular, que intentó estimular los canales de relación entre los artistas y la comunidad territorial, se fracturó debido a la irrupción del golpe militar y la llegada del régimen dictatorial cívico-militar. La Escuela de Danza y su Taller cerraron abruptamente el año 1976, posterior a seis años de trabajo en la institucionalidad universitaria, dejando a todos sus participantes con grandes interrogantes debido a que, por parte de rectoría. se manifestó un periodo de receso, como en la década de los sesenta, pero con la diferencia de que sus estudiantes no obtendrían ningún certificado de participación y asistencia que validara su paso por el Taller, que aunque fue comprometido por la institución, ${ }^{16}$ nunca llegó:

"con el golpe del 73 como era un concepto de alguna manera que se había politizado, porque también existían otras monitorías donde según se narraba, se ejercía el proselitismo político, se acabó inmediatamente el concepto de monitoría pero la malla curricular al interior de la escuela de danza continuó exactamente igual, y se le cambió el nombre de talleres de danza como un nombre de fantasía para evitar que se asociara dentro del ámbito del periodo de la junta militar este concepto de taller de danza que era muy light en relación a este otro que correspondía al periodo de Salvador Allende, pero la malla se sigue desarrollando, incluso alumnas que pertenecían al área de danza de la Casa municipal de la Cultura ingresan a estos talleres de danza y compartieron de alguna manera los horarios de clase que tenían a su vez las alumnas que pertenecíamos a la Escuela de Danza. Se produce

15 Financiadas por la Municipalidad de Valdivia, la Central Única de Trabajadores, la Dirección de Turismo, Impregnadora de Maderas S.A, Rotary Club, Asociación de Locomoción Colectiva y el Club de Bridge, ver El Correo de Valdivia, 10-VIII-1972.

16 Nueva estructura orgánica de Facultad de Bellas Artes a partir de $1^{\circ}$ de enero de $1977, \mathrm{~N}^{\circ}$ 007. Por disposición de rectoría quedaron en receso, según lo señalado, "temporalmente", el Instituto de Artes de la Representación y los Bachilleratos con mención en Artes Dramáticas, Danza y Artes de la Comunicación, en Archivo Secretaría General Universidad Austral de Chile. 
un acomodo de estos alumnos para no perderlos". (Waltraud Püschel, entrevista personal, 2017)

La desprotección institucional fue inminente. Debido a esta pérdida laboral y la situación política del país, muchos profesores de la Facultad migraron fuera de Valdivia y del país. De esta forma, terminó abruptamente el proceso de institucionalización, el que tomó una pausa, pero más larga de lo que muchos y muchas esperaban:

"bueno, mi paso por la Escuela de Danza llegó hasta el 1976, donde se congeló la carrera pensando que nosotros pagábamos como cualquier carrera de la Universidad Austral de Chile, porque yo incluso tengo guardados colillas de pago como cualquier carrera y nunca jamás nos dieron un certificado que acreditara los años de estudio que uno había tenido, la carrera fue congelada hasta los días de hoy, o sea se suponía que en cualquier minuto esto se iba a reabrir". (Ximena Schaaf, entrevista personal, 2017)

Bajo esta decisión, muchos alumnos quedaron fuera de un proyecto universitario que, desde su creación, integró el arte como arista necesaria de formación, pero que con el paso del tiempo significó un área de controversia debido a la inminente "anarquía" docente que significó para las autoridades la concurrencia de directores de talleres con proyecto artísticos diversos, determinando en 1981 el cierre de la Facultad de Bellas Artes con la finalidad de reemplazarla y crear, mediante una fusión, la Facultad de Filosofía y Humanidades. ${ }^{17}$

\section{Conclusiones}

El proceso de institucionalización de la danza corresponde a un periodo de transformaciones en torno a la comprensión de la necesidad de integrar en la academia valdiviana el arte escénico, lo que no estuvo alejado de problemas en torno al financiamiento universitario, desastres naturales e interés por parte de las autoridades de mantener el área. A partir de las tres historias de vida analizadas es posible comprender cómo estas situaciones forjaron trayectorias sociales y de oficio que dieron sentido a la construcción del campo de la danza en el sur de Chile. Por medio de su exposición, fue posible reconocer la diversa integración al campo de la danza de tres mujeres que a través de su vivencia expresaron las diversas contradicciones del proceso de institucionalización de las artes escénicas, sobre todo por los escasos medios económicos para

17 Informe Final sobre situación actual y futura de la H. Facultad de Bellas Artes: 8, en Archivo Secretaría General, Universidad Austral de Chile. 
su proliferación regional y nacional, de joven tradición cultural universitaria, a diferencia de otras casas de estudios centenarias.

La preocupación privada por levantar un modelo de universidad muy cercano a la europea de la primera mitad del siglo XX, representó la integración de las artes, en todas sus formas, al proyecto inicial de las "Bellas Artes", y que en relación a las universidades metropolitanas tuvo sus propias características y conformación. Es posible hablar que este proceso se insertó dentro de un momento modernizador desarrollista, que intentó, desde las esferas intelectuales, impulsar el arte desde el mundo privado, pero que finalmente decayó debido a que no significó una preocupación de largo plazo, lo que quedó ejemplificado en los constantes recesos acontecidos. Junto con esto, es necesario recalcar la labor de la Municipalidad de Valdivia, institución externa a la universitaria, que subvencionó un importante número de actividades artísticas.

De esta forma, cabe destacar la relevante participación de los bailarines en la consolidación del área en la Facultad, ya que por medio de sus academias dieron forma al campo externo e interno de la danza en la universidad, alimentando un espacio institucional incipiente y un proceso de institucionalización de las artes escénicas que finalmente los dejó desamparados, y que determinó la búsqueda de nuevos espacios de desarrollo, ya sea dentro o fuera de la región.

\section{Referencias bibliográficas}

\section{Fuentes primarias}

a) Publicaciones periódicas

El Correo de Valdivia, Valdivia, 1955-1976.

\section{b) Documentos publicados}

Programa básico de gobierno de la Unidad Popular (1969), Santiago.

Mensaje Presidencial Eduardo Frei Montalva (1968), Santiago.

XII Censo General de Población y I de Vivienda, Servicio Nacional de Estadística y Censos, 24 de abril de 1952.

Ley N ${ }^{\circ} 11.860$ que fija el texto refundido de la Ley de organización y atribuciones de las municipalidades (1955) 


\section{c) Archivos}

Archivo Secretaría General, Universidad Austral de Chile, 1955-1981.

Archivo personal, Ana María Cabello.

d) Entrevistas

Ximena Schaaf, 27-VI-2017.

Ana María Cabello, 3-VII-2017.

Waltraud Püschel, 27-VII-2017.

\section{Fuentes secundarias}

\section{a) Artículos}

Ponce, C. (2014). "Danza contemporánea independiente y política: movimientos y rupturas en Chile durante las décadas de 1970 y 1980", en Cátedra de Artes, № 15 , pp. 102-118.

Sanz, A. (2005). "El método biográfico en investigación social: potencialidades y limitaciones de las fuentes orales y los documentos personales", en Asclepio, Vol. 1, № 57, pp. 99-115.

\section{b) Libros}

Almonacid, F. (2004). Historia de la Universidad Austral de Chile (1954-2003). Su historia en el contexto universitario nacional. Valdivia: Ediciones Universidad Austral de Chile.

Almonacid, F. (2013). La industria valdiviana en su apogeo: (1878-1914). Valdivia: Ediciones Universidad Austral de Chile.

Bourdieu, P. (2011). Las reglas del arte. Génesis y estructura del campo literario. Barcelona: Anagrama.

Bourdieu, P. (2008). Cuestiones de sociología. Madrid: Akal//stmo Básica de Bolsillo.

Bourdieu, P. (2007). El sentido práctico. Buenos Aires: Siglo Veintiuno Editores.

Cancino, E., P. Berríos, C. Guerrero, I. Parra, K. Santibáñez y L. Vargas (2009). Del taller a las aulas. La institución moderna del arte en Chile (1797-1910). Santiago de Chile: LOM Ediciones. 
Cordovez, C., S. Pérez, M. J. Cifuentes, J. MacColl y A. Grumann (2009). Danza independiente en Chile. Reconstrucción de una escena (1990-2000). Santiago de Chile: Cuarto Propio.

Cifuentes, M. (2007). Historia Social de la danza, Santiago de Chile: LOM Ediciones.

Frei, E. (1993). 1911-1982 Obras escogidas (1931-1982). Colección Chile en el Siglo XX. Ediciones del Centro de Estudios Políticos Latinoamericanos Simón Bolívar y Fundación Eduardo Frei Montalva. Santiago de Chile: Editorial Antártica.

Guarda, G. (2001). Nueva Historia de Valdivia. Santiago: Ediciones Universidad Católica de Chile.

Hurtado, L. y Alcaíno, G. (2010). Retrato de la danza independiente en Chile. 1970-2000. Santiago de Chile: Ocho Libros.

Morales, E. (2014). Remembranzas de una Universidad Humanista. Valdivia: Ediciones Universidad Austral de Chile.

Petersen, N., E. Guard y L. Mancini (2013). Crónicas de la Sociedad Amigos del Arte. Valdivia: s/e.

Van de Maele, P. (1996). La Isla del alma mater, Historia testimonial de una Universidad... Valdivia: s/e. 